ISSN: 0213-2060

DOI: https://doi.org/10.14201/shhme20193722949

\title{
DOCUMENTOS HEBREOS DEL REINO DE NAVARRA. UNA REFLEXIÓN SOBRE SU ALCANCE HISTÓRICO-LINGÜÍSTICO ${ }^{1}$
}

\author{
Navarrese Hebrew Documents: Notes on their Historical and Philological Significance \\ Eunate MIRONES LOZANO \\ Depto. de Lengua Española. Facultad de Filología. Universidad de Salamanca. Plaza de Anaya, s/n. E-37008 \\ SALAMANCA. C. e.: eunatemironeslozano@usal.es
}

Recibido: 2018-05-08

Revisado: 2019-03-27

Aceptado: 2019-11-08

RESUMEN: La documentación medieval redactada en lengua hebrea y aljamía hebraica, preservada en los archivos navarros, es fuente de información indispensable para estudios históricos y filológicos. Navarra es uno de los territorios que más documentos medievales de este tipo conserva de entre los antiguos reinos hispánicos. Mostrar la cantidad y calidad manifiesta de estas fuentes es lo que motiva en primera instancia este estudio. Estos manuscritos permiten, por un lado, completar y poner en valor la información referida a judíos obtenida de las fuentes romances, con la que se construye en gran medida su historia en el reino navarro. Por otro lado, interesan a la filología per se como testigos directos del uso de la lengua hebrea y de lenguas vernáculas, como el euskera, en un contexto y un periodo de la historia determinado.

Palabras clave: Judíos; Navarra; Edad Media; Lengua Hebrea; Euskera.

ABSTRAC: The medieval documentation written in Hebrew and aljamia preserved in Navarrese archives is an essential source of information both for history and linguistics. Navarra, among the old Hispanic kingdoms, is one of the territories that conserves more medieval documents of this type. Therefore, what motivates this study, in the first instance, is to present the quantity and manifest quality of these sources. These manuscripts allow, on the one hand, to complete and to highlight the information about the Navarrese Jewish community obtained from Christian sources; with which history of Navarrese Jewry is

1 Se trata de documentos de carácter comunitario y privado, que se ocupan de asuntos monetarios y de organización interna de la comunidad, muy distintos de los pergaminos que contienen fragmentos bíblicos, de los que no hablaremos aquí por no hacer caso al objeto de estudio. 
DOCUMENTOS HEBREOS DEL REINO DE NAVARRA. UNA REFLEXIÓN SOBRE SU ALCANCE HISTÓRICO-LINGÜÍSTICO EUNATE MIRONES LOZANO

largely built. On the other hand, they interest philologically as direct witnesses of the use of Hebrew, and vernacular languages, like Basque, in a given period of history and in a particular historical context.

Keywords: Jews; Navarre; Middle Ages; Hebrew Language; Basque Language.

SUMARIO: 0 Introducción. 1 Descripción sumaria de los documentos. 1.1 Las taqqanot: ordenanzas de la comunidad. 1.2 Actas del tribunal rabínico: Bet-din. 1.3 Contratos matrimoniales: ketubbot. 1.4 Tributos sobre compraventas y préstamos. 2 Alcance informativo de la documentación. 2.1 Vida comunitaria. 2.2 El matrimonio y la familia. 2.3 Doble marco legal. 2.4 Economía. 2.4.1 Contribución a la Hacienda regia. 2.4.2 Ingresos. 3 Las lenguas de los judíos navarros 3.1 Lengua hebrea. 3.2 Lengua vasca. 4 Conclusión. 5 Referencias bibliográficas.

\section{INTRODUCCIÓN}

Los archivos navarros cuentan con un conjunto documental de enorme importancia para el estudio de la minoría judía que habitó el reino de Navarra en la Edad Media. Estos documentos, cuidadosamente editados en la serie Navarra Judaica, están escritos en romance navarro, en lengua hebrea, y en aljamía hebraica. La documentación escrita en lengua romance es árida, muy escueta y poco adornada, ya que su función contable es determinante. Se refiere, bien a los judíos como grupo de población, por su contribución a la corona en concepto de pecha; o bien de forma individual debido a sus propiedades y actividades comerciales ${ }^{2}$.

Por otro lado, contamos con los documentos redactados en lengua hebrea y aljamía hebraica, imprescindibles para perfilar con mayor claridad la historia de los judíos navarros. Se encuentran en el Archivo General de Navarra (AGN), Sección de Comptos, Caj. 192; en el Archivo Municipal de Tudela (AMT) y en el Archivo de la Catedral de Pamplona (ACP). No nos detendremos aquí a hablar de su soporte escriturario, estado físico o dimensiones; datos estos que se pueden consultar en la edición de R. Magdalena y Y. T. Assís ${ }^{3}$. Son en total 61 documentos, que en piezas de archivo suman 68, fechados entre principios del siglo XIV y finales del siglo Xv. Contienen, en orden de importancia: unas ordenanzas de la aljama de los judíos de Tudela; ketubbot (contratos matrimoniales); ordenanzas de la sisa del vino y de la carne; una sesión del tribunal rabínico; libros del veinteno y de la alcabala; y libros de particulares donde se registran bienes, préstamos y cartas de deuda ${ }^{4}$.

2 Los documentos escritos en romance se publican en la serie Navarra Judaica (NJ), compilada entre 1995-2003 por Juan Carrasco, Eloísa Ramírez Vaquero y Fermín Miranda, y publicada por el Gobierno de Navarra.

3 Assís, Yom Tov; Magdalena Nom de Déu, José Ramón y Lleal Galcerán, Coloma. Navarra hebraica. Estudio lingüistico de la aljamía romance en los documentos hebraiconavarros. Barcelona: Universidad de Barcelona, 2003.

4 Documentación publicada al completo en la serie Navarra Judaica, vid. LACAVE, José Luis. Los judios del reino de Navarra. T. 7, Documentos hebreos 1297-1486. Pamplona: Gobierno de Navarra, 1998. Y. Baer y J. M. Millás Vallicrosa publicaron antes algunos documentos (vid. referencias bibliográficas). 
El grupo de documentos que contiene los libros de contabilidad privados es el que más interesa al estudio. Su tipología no es la habitual en el estudio de la historiografía hebrea. No están redactados por intelectuales, rabinos o filósofos; no son responsa, ni comentarios bíblicos o rabínicos. Son un tipo de documento único en su género y de enorme valía para el estudio histórico y lingüístico de esta comunidad. Redactados en hebreo y aljamía hebraica, sin atender a norma culta alguna, dan noticia del conocimiento real de la lengua hebrea por parte de quienes los elaboran. Muestran que el hebreo no estaba restringido a la liturgia sinagogal, sino que era lengua viva. En cuanto a los textos y fragmentos aljamiados, resultan de inestimable valor para el estudio del sociolecto 'judeonavarro' del siglo XIV ${ }^{5}$. Por último, amplían el repertorio onomástico con nombres no recopilados antes y escritos con grafía hebrea que, en el caso de los nombres vascos, ofrecen información de interés para la fonología histórica vasca ${ }^{6}$.

\section{DESCRIPCIÓN SUMARIA DE LOS DOCUMENTOS}

\subsection{Las taqqanot ${ }^{7}$ : ordenanzas de la comunidad}

De los manuscritos hebreos que escapan a la temática estrictamente financiera, el más importante de los conservados es el que recoge las ordenanzas de la aljama de Tudela, redactadas entre los años 1297 al 1305. Es una muestra única de este tipo de documento para la Península Ibérica, junto con el de las ordenanzas de Valladolid de $1432^{8}$. Contiene un cuerpo de normas reguladoras de la vida comunal, que elaboraban y ratificaban las autoridades de la aljama', y que el resto de los miembros de la comunidad generalmente aceptaban. Los grandes de la comunidad eran miembros de familias tudelanas de renombre y detentaban la máxima autoridad, puesto que entonces no existía en Navarra la figura del Gran Rabino. El primer judío así titulado será Juce Orabuena, «raui mayor de los judios del regno» y médico personal de Carlos III (1361-1425).

En las ordenanzas se dedica un largo párrafo a la exención de deudas y al aplazamiento de hipotecas, especificando con detalle todos los supuestos y sus adecuadas resoluciones. Se ocupan también de la regulación de los préstamos y las penas por enfrentamientos violentos y discusiones en la sinagoga. Uno de los apartados más desarrollado e interesante de las ordenanzas es el que refiere las penas por malsinería. Se fijan las

5 Assís, Magdalena Nom de Déu y Lleal Galcerán, Navarra hebraica.

6 Vid. Mirones Lozano, Eunate. "Mehe: un apellido vasco escrito en aljamía hebraico-navarra». Fontes linguae vasconum, 2009, vol. 41, n. ${ }^{\circ} 110$, pp. 117-124. su edición.

Nos decidimos en todos los casos por la transcripción de los términos hebreos que utiliza Lacave en

8 Moreno Koch, Yolanda. Fontes Iudaeorum Regni Castellae. V. De iure hispano-hebraico. Las Taqqanot de Valladolid de 1432. Salamanca: Universidad Pontificia de Salamanca, 1987. Sobre las ordenanzas de Toledo, vid. Llamas, P. J. «Documentos para la historia jurídica de las aljamas hebreas de Toledo y Molina». Religión y Cultura, 1932, vol. 19, pp. 263-276.

9 Los ordenamientos de comunidades judías más antiguos que se conservan datan de fines del siglo $\mathrm{x}$ y principios del xi, vid. Neusner, Jacob. «Studies on the Taqqanot of Yavneh». Harvard Theological Review, 1970, vol. 63, pp. 183-198. 
DOCUMENTOS HEBREOS DEL REINO DE NAVARRA. UNA REFLEXIÓN SOBRE SU ALCANCE HISTÓRICO-LINGÜÍSTICO EUNATE MIRONES LOZANO

condenas de aquellos que con su falso testimonio causaran daño o perjuicio a la comunidad, o a un miembro de esta y las consecuencias de tal delito. Se trata también la disposición de las herencias, determinándose cómo repartir la herencia de la mujer que queda viuda. El último apartado se ocupa de la venta de bienes inmuebles, asunto igualmente regulado por las autoridades de la comunidad, que han de supervisarlo para evitar el fraude.

\subsection{Actas del tribunal rabinico: Bet-din}

Los archivos navarros conservan una pieza documental excepcional que recoge una sesión del tribunal rabínico del año $1467^{10}$. En ella se resuelve la demanda presentada por una judía de nombre Fatbuena, viuda de Salomón Abenabez. La viuda reclama el pago de su contrato matrimonial, la dote y donación aparte que le hiciera su difunto marido. Dentro de las actas se inscriben el contrato matrimonial, el testamento del difunto y una valoración de los bienes muebles e inmuebles que este dejó al morir.

Salomón instituye como heredero universal a su mujer; derecho que le pertenece por su contrato matrimonial. Dona asimismo una viña a la Sinagoga Mayor para la expiación de su alma, y un florín a cada una de las sociedades de la comunidad. Ordena que a cada uno de sus hijos se le entregue cinco florines, para evitar reclamaciones futuras. Finaliza con una fórmula que garantiza la integridad del testamento, y encarga esta labor a los testigos, que lo redactan con el lenguaje adecuado y recuerdan que se ha ejecutado con plena consciencia del testador, sin ninguna coacción.

Un año después de la muerte de Salomón, los bedines ${ }^{11}$ que se ocupan de la demanda deciden inventariar sus bienes. La lista de los bienes inmuebles que registran difiere en parte de la lista que describe la donación de Salomón a Fatbuena en sus esponsales. Hacen jurar a la viuda que los bienes mencionados en la donación no hayan sido vendidos ni hipotecados, anotan el valor total de la tasación y, tras el análisis detallado de la documentación presentada por la viuda, deciden responder afirmativamente a su petición ${ }^{12}$. Finaliza con la ratificación que hace irrevocable su decisión.

\subsection{Contratos matrimoniales: ketubbot}

«Sé mi esposa según la Ley de Moisés e Israel, y yo te serviré, honraré, mantendré y sustentaré a la manera de los varones judíos que sirven, honran, mantienen y sostienen a sus mujeres fielmente...» ${ }^{13}$.

10 No se sabe de otro documento de este tipo conservado en los archivos peninsulares. Lacave publica su estudio; vid. Lacave Riaño, José Luis. «Un interesante documento hebreo de Tudela». En Exile and diaspora. Studies in the History of the Jewish People presented to Professor Haim Beinart. Jerusalén: Consejo Superior de Investigaciones Científicas-Instituto Ben-Zvi, 1991, pp. 131-145. Sobre el funcionamiento interno de estos tribunales, vid. Motis Dolader, Miguel Ángel. "Estructura interna y ordenamiento jurídico de las aljamas judías del Valle del Ebro». En Iglesia Duarte, José Ignacio de la (coord.). II Semana de Estudios Medievales. Logroño: Instituto de Estudios Riojanos, 1992, pp. 111-152.

11 Bedín: oficial del poder fiscal y ejecutivo entre los judíos.

12 Lacave, Los judios del reino de Navarra, n. ${ }^{\circ} 430$.

13 Ibidem, n. ${ }^{\circ} 422$. 


\section{DOCUMENTOS HEBREOS DEL REINO DE NAVARRA. UNA REFLEXIÓN SOBRE SU ALCANCE HISTÓRICO-LINGÜÍSTICO EUNATE MIRONES LOZANO}

Así comienza la ketubbá más antigua que se conserva en los archivos navarros. Los contratos matrimoniales, denominados en la tradición religiosa judía ketubbot, constaban de una serie de secciones con cláusulas ineludibles y bien especificadas que protegían los derechos de la mujer en los supuestos de viudedad o divorcio. Las ketubbot navarras siguen las indicaciones del Sefer ha-Šetarot de Yehudá al-Bargeloní en lo concerniente al cuerpo principal ${ }^{14}$ : el novio aporta un móhar (מוהר) o 'principal', que es el precio simbólico que se paga por la esposa a los padres de esta y que se completa con el 'incremento', toséfet (תוספת). La familia de la novia aporta la dote o nedunyá (נדוניא), que se califica como ș'on barzel, (צאן ברזל), tipo especial de arriendo en el que el título de propiedad de los bienes quedaba en manos de la esposa, mientras la posesión y el manejo de esos bienes correspondía al esposo, quien podía usarlos para sus necesidades; si bien tenía que garantizar su retorno a la esposa a la disolución del matrimonio. El texto principal incluye también una garantía, aharayut (אחריות), por parte del marido, que se compromete a que su esposa reciba el pago de su deuda como acreedora de sus bienes cuando el tiempo lo precise. Se concluye esta parte con las firmas de los testigos. Normalmente a este cuerpo principal, redactado con letra cuadrada, se le ańade un texto escrito en cursiva. Suele comenzar indicando 'la donación aparte', mataná lehud (מתוד) מתנה), que hace el novio y que consiste, por lo general, en una propiedad inmueble, que se convertiría previsiblemente en el domicilio familiar.

La ketubbá mencionada arriba, suscrita en el año 1300, recoge el acuerdo matrimonial entre dos novios navarros de los que no tenemos más información, más allá de su mención. El valor principal de este manuscrito reside en su antigüedad, ya que es la ketubbá más antigua de las conservadas para Navarra, y la única con ornamentación zoomórfica $^{15}$. Se conserva una segunda ketubbá de 1486, firmada también en Tudela, que establece el matrimonio de Moshé del Gabay con la viuda Solbella. La donación aparte, mataná leḥud, consistió en una casa en Cascante libre de cargas y una viña también en Cascante. Otras kettubot navarras, conservadas en peor estado y menos completas, refieren los matrimonios de: Samuel ben Yom Tob Suri y Jamila, en Milagro 1309; Abraham ben Isaac ben David y Fatbuena, en Tudela 1324; Salomón Abenabez y Fatbuena, en Tudela 1441; Judá ben Saadia ben Natán y Dueña, en Tudela 1352; Abraham Evenzoher y Raquel, en Tudela 1476; Samuel Azafar y Buena, en Tudela 1480; y, por último, la de Natán de Narbona y Dueña, que tiene lugar en 1482 en Borja, pero cuyo apéndice con nuevas cláusulas se redacta en Tudela, vinculando así el contrato a esta ciudad ${ }^{16}$.

14 Lacave Riaño, José Luis. «El contrato matrimonial entre los judíos navarros». Estudios Mirandeses, 1988, vol. 8, pp. 91-99.

15 Se recomendaba decorar todos los espacios libres que hubiera en un escrito, para evitar con ello que se manipulasen las cláusulas y así alterar el contrato matrimonial (Sefer ha-Tashbetz (Lvov, 1858 [Cremona 1555/1556]), Responsum 6.

16 Lacave recoge treinta documentos de este tipo en su monografía sobre las ketubbot conservadas en la Península Ibérica; vid. Lacave, José Luis. Medieval Ketubot from Sefarad. Jerusalén: Magnes Press, 2002. Ricardo Muńoz Solla ha publicado un artículo sobre interesantes fragmentos de ketubbot castellanas: «Dos "ketubbot" castellanas y otro fragmento hebreo del Archivo de la Real Chancillería de Valladolid». Sefarad, 2014, vol. 74, n. ${ }^{2}$ 2, pp. 343-368. Vid. también, Castaño González, Javier. “Ketubbot” en-cubiertas: fuentes para el estudio del matrimonio judío en Jaca y los Almosnino». Sefarad, 2009, vol. 69, n. o 1, pp. 43-73. 
DOCUMENTOS HEBREOS DEL REINO DE NAVARRA.

UNA REFLEXIÓN SOBRE SU ALCANCE HISTÓRICO-LINGÜÍSTICO

EUNATE MIRONES LOZANO

\subsection{Tributos sobre compraventas ${ }^{17}$ y préstamos}

Un grupo muy numeroso de documentos contiene los libros de registro de bienes de judíos particulares de diferentes localizaciones dentro del reino. En ellos se anotaban los impuestos que habían de pagar por la compraventa de distintas mercancías. En concreto, se han conservado libros del veinteno y de la alcabala, que registran tributos sobre la venta de carne, seda, cueros, plata y pieles ${ }^{18}$. Contienen las declaraciones ante testigos de los carniceros sobre lo vendido por semana, y asimismo las declaraciones de los matarifes respecto del ganado degollado ritualmente cada semana ${ }^{19}$. Se conserva, asimismo, un documento que contiene las sisas del vino y de la carne que cobraba la aljama y que era satisfecha por el vendedor. La aljama era quien gestionaba este impuesto, y lo entregaba en arriendo al mejor postor. La tasa del vino era de un dinero por cada carapito $(11,77$ litros) o de una meaja $a^{20}$ si el producto era mezcla de agua y vino. El vendedor de carne debía pagar de cada libra carnicera un dinero, de cada cabrito o cordero seis dineros, y de las entrañas un dinero de cada seis ${ }^{21}$.

Por otro lado, los libros que registran los préstamos contienen listas de deudores, identificando con mucho detalle al deudor y sus garantes, y precisando lo debido con sus plazos de pago. Se describen también las dificultades de cobro de algunas deudas, justificando así el impago del impuesto que correspondía pagar de haberlas podido cobrar.

\section{AlCANCE informativo de la documentación}

\subsection{Vida comunitaria}

El manuscrito que contiene las ordenanzas de la comunidad judía de Tudela da noticias precisas del funcionamiento interno de esta aljama y, por extrapolación, del resto de aljamas navarras, siendo la tudelana la guía y pauta de todas las demás. Estas disposiciones reguladoras, junto con la relación de multas previstas por su incumplimiento, son testimonio fidedigno e incontestable de la vida intramuros de las juderías. Las taqqanot podían ser

17 Para entender el funcionamiento de la hacienda navarra, vid. CARrasco Pérez, Juan. «Notariado y Hacienda Pública en el reino de Navarra. El devengo de los sellos del rey. 1294-1414». Príncipe de Viana, 2013, vol. 74, n. ${ }^{\circ}$ 257, pp. 111-191; ÍD. «El crédito judío en el reino de Navarra, según los padrones de deuda hebreos (1323-1328)». En Val Valdivieso, M.a Isabel del y Martínez Sopena, Pascual (coords.). Castilla y el mundo feudal. Homenaje al profesor Julio Valdeón. Valladolid, 2009, vol. 2, pp. 237-249. Vid. también, Mugueta Moreno, Íńigo. "Las demandas del rey de Navarra: vocabulario, discurso e identidades fiscales (1300-1425)». Anuario de Estudios Medievales, 2014, vol. 44, pp. 911-943.

18 OngaY, Nelly. El registro del «veinteno» en Tudela. 1362. Mendoza: Universidad Nacional de Cuyo, 1997. Sobre fiscalidad navarra, vid. García Fernández, Ernesto y Vítores Casado, Imanol (eds.). Tesoreros, "arrendadores" y financieros en los reinos hispánicos. La Corona de Castilla y el Reino de Navarra (siglos XIVXVII). Madrid: Instituto de Estudios Fiscales, 2012.

19 Lacave, Los judios del reino de Navarra, n. ${ }^{\text {os }} 33$ y 34.

20 Moneda antigua de Castilla, de vellón, que valía la sexta parte de un dinero (Cfr. Moliner, María. Diccionario de uso del español. Madrid: Gredos, 1970, T. 2, s. v.).

21 LaCave, Los judios del reino de Navarra, p. 161. 
temporales o permanentes, y la decisión de que una norma permaneciera inalterable acarreaba, en no pocos casos, grandes problemas. En ocasiones, por no adaptarse ya una norma determinada a la realidad del momento, o por presentar dudas en su interpretación y ejecución, se hacía necesaria su anulación o transformación, y era muy complicado volver atrás en una decisión para cuya constitución había sido necesaria la confirmación y acuerdo de los dirigentes de la aljama y del rabino local. Una vez establecida y ratificada la normativa, era ley inapelable durante el periodo de tiempo correspondiente y su incumplimiento conllevaba la posibilidad de excomunión. Si bien, la amenaza de excomunión no era más que una forma efectiva de mantener la disciplina, quedando normalmente en simple amenaza ${ }^{22}$.

En principio, las cuestiones que tratan estas ordenanzas responden a necesidades concretas y circunstanciales de la comunidad judía de Tudela a finales del siglo XIII y principios del xIV, y a esta afectan únicamente. Sin embargo, los asuntos que tratan difieren poco de aquellos que afectan a comunidades judías de otros lugares, no solo del reino navarro, sino también del resto de la Península. Los problemas que desestabilizan el funcionamiento interno de las aljamas se replican con considerable similitud en distintas épocas y lugares, como por ejemplo la malsinería o los comportamientos violentos, que se atienden con el mismo énfasis en las taqqanot de Valladolid y en las de Tudela. Los delitos fiscales preocupan asimismo a todas las normativas, que tratan de evitar que individuos de la aljama se beneficien irregularmente de exenciones fiscales o de cualquier gasto comunitario, perjudicando a sus conciudadanos en el reparto de los gastos comunes. La regulación de préstamos y la disposición de las herencias son, del mismo modo, objeto de especial atención en las regulaciones conocidas.

La preocupación por detallar los castigos sobre estas conductas inadecuadas es un claro indicador de que tenían lugar persistentemente. Son muestra también de las fuertes tensiones que se libraban en la comunidad, así como de la severa observancia que imponía la religión judía. Aunque la documentación hebrea no indica si las ordenanzas se llevan a efecto $^{23}$, los delitos penalizados se reflejan abundantemente en la documentación romance. Por comportamientos violentos: «De Juce Leui, judio de Tafailla... por auer ferido al dicho Jaco Beniamin de mutchos colpes» ${ }^{24}$. Por impago de deudas: Abraham Farrach, judío de Pamplona, es condenado "por cierta deuda que tenia a Johan de Calua» ${ }^{25}$; por falsificación de documentos oficiales o moneda: «De Jento Aziz, judio de Viana... fue acusado como eill avia falsifficado e mudado ciertos padrones de tassa de la dicha aljama» ${ }^{26}$; "De Mosse Benayon... judio d'Estella el quoal fue acusado eill auer billonado e trabuquado la moneda del regno ${ }^{27}$.

22 Existían distintos niveles de excomunión según la infracción cometida, que iban, desde un aislamiento absoluto de la comunidad con carácter indefinido (herem), hasta una expulsión temporal con un apartamiento mucho menos estricto (nidduy).

23 Baer, en su análisis de las ordenanzas de Valladolid, señala que: «cabe la duda de si las aljamas usaron alguna vez de estos derechos a lo largo del siglo xv. Ninguna mención hay de ello en los documentos ni tampoco en la gran literatura antijudía que no lo habría dejado pasar en silencio» (Cfr. BAER, Ytzhak. Historia de los judios en la España cristiana. Madrid: Altalena, 1981, p. 523).

24 AGN, Comptos, Reg. 391, fol. CCCCXXXVv.

25 AGN, Comptos, caj. 145, n. ${ }^{\circ} 15$, fol. IVv.

26 Ibidem, fol. CCCXIV.

27 AGN, Comptos, Reg. 416, fol. CCCLV. 
DOCUMENTOS HEBREOS DEL REINO DE NAVARRA.

\subsection{El matrimonio y la familia}

«Aquel que pasa sus días sin una esposa, no tiene felicidad, ni bendición, ni bien» (TB Yebamot 62b).

El matrimonio es uno de los preceptos primordiales para el judaísmo, un precepto a seguir; es el estado social perfecto. La institución de la familia era un pilar fundamental que ayudaba a mantener el equilibrio de la comunidad. La mujer judía, al igual que la cristiana, era educada en época medieval únicamente para el matrimonio y la maternidad. El marido tenía autoridad ilimitada sobre ella y potestad absoluta sobre sus bienes, los que aportaba al matrimonio como dote, y los que heredaba o adquiría con su trabajo. La mujer se limita a las obligaciones derivadas de su condición de esposa y madre. El contrato nupcial que describimos en el apartado a propósito da cierto amparo jurídico a la mujer, al tratar las condiciones económicas de los contrayentes, especificando todos los supuestos posibles, caso de que el matrimonio se disolviera por defunción del marido, divorcio u otra causa.

Las kettubot navarras conservadas son testigos del rigor con el que los judíos navarros cumplían el precepto básico del judaísmo de unirse en matrimonio; así como su preocupación por ajustarse jurídicamente a las normas religiosas vigentes. Sin olvidar la cuestión económica, fundamental para asegurar la pervivencia digna y sostenible de los contrayentes, y por extensión de la comunidad en la que vivían. Ya dijimos que la sección escrita con letra cuadrada es en gran medida protocolaria y da poca información más allá de la fecha, lugar y nombre de los novios y familiares comprometidos en el contrato. Sin embargo, la parte escrita en cursiva, 'la donación aparte', ofrece información valiosa de los esposos, sus familias y propiedades. Tenemos ejemplo de ello en la ketubbá de 1486 firmada en Tudela, la única que conserva esta parte escrita en cursiva y que nos da noticia de la posición en la comunidad de las familias implicadas, las de los esposos y las de los testigos, así como de la moneda en curso. También se puede colegir el estatus y la localización de la judería de Cascante en la que vivirán, ya que en la descripción del inmueble que dona el novio se especifican los lindes de este ${ }^{28}$.

\subsection{Doble marco legal}

La existencia de las ordenanzas dictadas por la comunidad judía de Tudela, y el testimonio de las penas ejecutadas en beneficio de la Corona, prueban la presencia en el reino de Navarra de un doble marco legal, delimitado por las obligaciones contenidas en las leyes rabínicas y por los mandatos de los fueros navarros respecto a los judíos. Sin olvidar que la autonomía de los judíos para ejercer su ley y decidir sobre asuntos internos era limitada, ya que no dejaba de ser una concesión de la Corona, que decidía y controlaba todo en última instancia. Si la aplicación de una ley judía, aunque tratara asuntos

28 Lacave, José Luis. "Tres nuevas ketubbot españolas». En The History of the Jewish People. From the Second Temple period until the Middle Ages. Jerusalén, 1985, vol. 1, pp. 91-96. 
estrictamente internos, afectaba de algún modo a cuestiones más allá de la comunidad, quedaba invalidada de inmediato. Así pues, se resolvían causas de carácter religioso y civil que incumbían única y exclusivamente a los judíos, y cuyas consecuencias no transcendían los límites de su comunidad. La justicia penal correspondía a la Corona siempre, del mismo modo que la percepción del contante devenido de las multas se destinaba a la Hacienda regia. Es significativo el número de querellas referidas en los fueros, originadas por desacuerdos en asuntos de empeños, deudas y préstamos, en las que estaban implicados judíos del reino ${ }^{29}$.

Dina de-maljuta dina: la ley del reino es ley. Esta norma consignada en arameo en el Talmud indicaba, ya desde tiempos del Imperio romano, que los judíos debían someterse en la diáspora a la ley civil del lugar en el que residieran. Sin embargo, como acabamos de decir, la aljama goza del privilegio de resolver y juzgar sus asuntos internos, y lo hace por medio de un tribunal rabínico, el bet-din: tanto los asuntos relativos a impuestos y finanzas, como los litigios de índole religiosa, siempre y cuando no afecten a miembros ajenos a la comunidad judía. Una asamblea elegía a los jueces, dayyanim, que ejercían su cargo durante un año y tenían la capacidad de juzgar internamente demandas, contiendas y transgresiones religiosas. Podían multar y castigar a quienes consideraran culpables de los delitos imputados. Su decisión final debía estar apoyada por un rabino y «tres hombres buenos de la ciudad». Los judíos preferían por lo general presentar sus causas ante tribunales rabínicos, que seguían sus propias leyes y conocían mejor las circunstancias del demandante y la naturaleza de su demanda, aunque, cuando uno de los litigantes no acataba la sentencia del tribunal judío, el interesado podía acudir a un tribunal cristiano, si bien lo más común era que las contiendas entre judíos se dirimieran ante un tribunal rabínico.

La pieza documental mencionada más arriba, que recoge una sesión del tribunal rabínico, es una prueba irrefutable de esta independencia para resolver asuntos internos, así como de la capacidad jurídica de los judíos navarros, expresada en fórmulas legales que, por otro lado, no difieren en esencia de las de otras comunidades judías peninsulares. En la donación que se incluye en la demanda se describe con detalle los bienes del difunto, permitiéndonos deducir el estatus de una familia pudiente de la comunidad judía más importante del reino de Navarra, la tudelana. El bien más importante era la casa principal dentro del castillo, morada de la familia. A esta se suman otras casas, con sus dependencias y muebles dentro de la aljama, una tierra virgen a la vera del río, junto con diez viñas en producción localizadas en distintos lugares de la ciudad. No se menciona otro negocio distinto del vinícola. Se trata cada supuesto con mucho detalle y atención ya que, una vez que el tribunal tome su decisión última y se rubrique la sentencia, será difícilmente impugnable.

El documento nos da noticia, asimismo, de en qué medida la inestabilidad política del reino afecta a una familia acomodada. Es el año 1467, y el reino lleva tiempo envuelto en una guerra civil indefinida que dificulta la prosperidad de los negocios de sus habitantes, cristianos como judíos. La guerra atravesaba su momento más crudo, la población

29 García Arancón, Raquel. «Marco jurídico y proyección social de las minorías navarras: judíos y mudéjares (siglos XII-Xv)». Iura Vasconiae, 2007, vol. 4, pp. 459-516, esp. p. 468. 
DOCUMENTOS HEBREOS DEL REINO DE NAVARRA.

disminuía y se arruinaba. Las cortes del reino se veían obligadas a conceder ayudas por separado a don Juan y a su hijo, multiplicando así sus requerimientos en perjuicio de la población. La Hacienda Real estaba empobrecida, por lo que se recurría a impuestos extraordinarios. Cuando la viuda responde ante los bedines por los bienes heredados, alega que había vendido una parte para pagar el impuesto de la aljama y otra parte para pagar a los prestamistas. $Y$ añade que los bienes muebles habían sido utilizados como garantía del préstamo que había pedido el año anterior para la manutención de sus hijos. En principio, la viuda no poseía formalmente estos bienes, pero alega que si no se los conceden la familia entera se vería abocada a la ruina. Los bedines comprenden sus circunstancias y conceden que ha dispuesto de ellos obligada por la necesidad.

Además de los impuestos directos, los judíos tributaban sobre bienes de consumo que comercializaban, como el pan, la carne, el pescado y el vino. La viuda tendría que hacer frente al impuesto sobre el vino. Dada la precaria situación general, es muy probable que disminuyeran las ventas y no se pudieran trabajar las tierras adecuadamente; razón por la que recurre al préstamo para la manutención de la familia y el pago de los impuestos. La flexibilidad de los oficiales al cargo, que consideran las circunstancias comprometidas de la viuda, da idea de la importancia que la estabilidad familiar supone para la comunidad. La familia es el núcleo básico de organización social en las comunidades hebreas de la Edad Media. La familia en sentido estricto, matrimonio con o sin hijos, y en el sentido más amplio considerando a todos aquellos parientes ligados por lazos de sangre.

\subsection{Economía}

\subsubsection{Contribución a la Hacienda regia}

La abundante documentación conservada en romance referida a judíos navarros, junto con la documentación escrita en hebreo y aljamía, nos permite conocer cómo y cuánto participaba esta minoría de la economía del reino. Sabemos, por la documentación romance, que la principal contribución económica de los judíos era la llamada pecha de los judios, pago por lo general anual. Solía ser una cantidad considerable de dinero cuya cuantía se acordaba entre el rey y los representantes de las aljamas, en función de las posibilidades económicas de los contribuyentes. En ocasiones se reducía significativamente por remisiones debidas a guerras, malas cosechas, etc. Las exenciones también tendrían lugar a título personal.

Parece claro, en cualquier caso, que los ingresos que se obtenían de esta minoría eran substanciosos y de cierta garantía $a^{30}$. El capital obtenido por la corona de las penas y multas impuestas a los judíos era también una fuente considerable de ingresos. Estos delitos,

30 Un ejemplo, entre otros, es un pago que hace la reina dońa Blanca sobre la aljama de los judíos de Val de Funes: «fazemos vos saber que nos avemos ordenado et por las presentes ordenanças que nuestro amado et fiel camarlengo mossen Garcia de Agramont haya de haber et recebir entregament aquellas trezientas libras carlines las quales las aljamas de los judios de Vall de Funes le sont obligados dar et pagar» (AGN, Comptos, caj. 125 , n. $\left.{ }^{\circ} 29, \mathrm{~V}\right)$. 


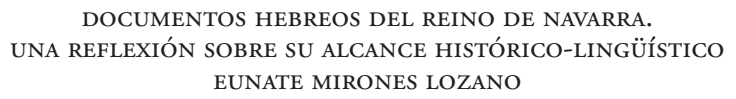

junto con la cantidad que se había de pagar por haberlos cometido, se relacionan en los libros de los recibidores, concretamente en el apartado «de homicidios, medios homicidios e calonias $\aleph^{31}$, del que se ocupa el Procurador Fiscal. La minoría judía tiene en este apartado su correspondiente representación por infracciones varias: impago de deudas; enfrentamientos entre personas causándose daños graves; falsificación de documentos oficiales y manipulación de la moneda oficial a espaldas de las autoridades. Asimismo, los judíos participan con el resto de la población en las ayudas extraordinarias que solicitan los reyes, casi siempre por razón de la guerra. Y contribuyen, por fin, con los impuestos indirectos que gravan la compraventa de distintos productos. Los documentos hebreos que aquí estudiamos dan claro reflejo de ello. En concreto, se ve claro en los libros del veinteno y la acabala que especifican con mucho detalle los gravámenes correspondientes a la venta de carne, vino, seda, cueros, pieles y zapatería ${ }^{32}$.

\subsubsection{Ingresos}

Los registros que contienen libros de cuentas de judíos particulares, de los que hablamos en apartados anteriores, ofrecen una información directa y valiosísima del funcionamiento de la economía judía. Nos dan testimonio de cuáles eran sus fuentes de ingresos, de donde obtenían el dinero que les permitía vivir y hacer frente a los impuestos con los que les gravaba la Corona. Su lectura nos confirma que poseían casas y tierras, recaudaban impuestos, vendían diversas mercancías, y se ocupaban de variados oficios, que combinaban en ocasiones con el préstamo de dinero.

Los judíos podían adquirir tierras, en régimen de arriendo, procedentes de las llamadas «heredades reales», de cuyos beneficios podían disfrutar por un periodo de tiempo determinado, y por las cuales pagaban un censo al rey. Podían también tener la propiedad "completa» de una tierra, por lo que se deduce de algunos testimonios ${ }^{33}$; y por lo que dice al respecto el Amejoramiento de 1330: «Plázenos et tenemos por bien, porque los iudios et los moros puedan cobrar sus deudas e pagar sus peytas, que... puedan comprar de las heredades de los cristianos, et quando querrán et menester los fará, que las puedan vender $\aleph^{34}$. Aparte de la adquisición de la tierra por medio de compra, trueque o herencia, existe otra posibilidad: es la tierra dada como prenda de un préstamo, obtenida

31 La calonia era la multa o pena pecuniaria que se pagaba al rey, al juez y en algunos casos a la parte afectada por un delito cometido; el "homicidio" era la pena que había de pagarse en caso de un delito grave, aparte de recibir el encausado, en la mayoría de los casos, la pena capital. Vid. Zabalo Zabalegui, Javier. La Administración del Reino de Navarra en el siglo XIV. Pamplona: Eunsa, 1973, pp. 186-193.

32 LaCave, Los judios del reino de Navarra, pp. 184 y ss.

33 Abraham Benjamin, que ejerce de platero en Tudela, reconoce en una carta cómo «Paschoal, vezino de la dicha ciudat avedes vendido, allienado e trasportado a mi un huerto vuestro situado en Mosquera", AMT, Protocolos Tudela. Bernart de Morlanes. 1456, fols. X-XII (sin foliar). En 1453, también en Tudela, Ximeno de Corella vecino de la ciudad da en trueque un majuelo a Açach Afla (sic), «judio habitant en la dicha ciudat por un otro malluelo» (AMT, Protocolos Tudela. Miguel Garceiz del Costal. 1427-1495, fol. Iv.

34 Ilarregui, Pablo y Lapuerta, Segundo (eds). Fuero General de Navarra. Pamplona: Imprenta Provincial, 1869 ("Amejoramiento», cap. XVII, p. 151). 
DOCUMENTOS HEBREOS DEL REINO DE NAVARRA. UNA REFLEXIÓN SOBRE SU ALCANCE HISTÓRICO-LINGÜÍSTICO EUNATE MIRONES LOZANO

por el acreedor si el prestatario no es capaz de saldar su deuda. El deudor ofrece la tierra como garantía y, no pudiendo pagar su deuda, ha de satisfacer al acreedor con las tierras entregadas en prenda. Por ejemplo, Haym Frances, judío argentero de Tudela, adquiere en 1377 unos huertos y unas piezas embargadas a Sancho Pérez de Leoz, por una deuda que este último tenía pendiente con Açach Saprut y no había satisfecho ${ }^{35}$. Otro ejemplo significativo es el de Abraham Enxoep, recaudador de la imposición de la merindad de Estella desde 1399, judío acaudalado y propietario de tierras, condenado por la Corte por infracciones cometidas en el ejercicio de su cargo. En el inventario que se hace de sus bienes se encuentran numerosas heredades que se venden para cubrir la multa que le impone la Corona ${ }^{36}$. Al igual que ocurría con las tierras, existían casas de propiedad soberana, por las que sus habitantes han de pagar un censo anual; o bien casas que se poseían de pleno derecho. Por ejemplo, en 1443 dońa Astruga, propietaria de unas casas en Tudela, decide empeńarlas a don Yehuda de la Rebiça para pagar la dote de su hija. Don Yehuda podrá disponer de ellas durante cinco ańos, y del beneficio que de ellas obtenga descontará de la deuda dos florines por año. Pasado el plazo acordado, si no le devuelven el dinero debido, seguirán en su posesión hasta que le sea devuelto el dinero prestado ${ }^{37}$.

Una fuente de ingresos considerable provenía del arriendo de impuestos y de los préstamos. Las noticias sobre judíos arrendadores de tributos solo se reflejan en la documentación cristiana; como prestamistas aparecen en documentación hebrea y cristiana. El préstamo de dinero suponía un importante ingreso, según se refleja en los documentos; de ahí que sirviera de poco la extensa normativa desarrollada, tanto por la Iglesia como por la tradición judía, para limitar su ejercicio. La Iglesia, por motivos que provenían, en parte, de la ancestral idea de que el comercio del dinero provocaba la codicia, prohibía a los cristianos prestar a usura, si bien la prohibición no les disuadía de hacerlo. Los cristianos también prestaban dinero, aunque, sometidos como estaban al peso de la ley eclesial, no se permitían hacerlo tan abiertamente ${ }^{38}$. La religión judía, a su vez, no permitía el préstamo entre correligionarios ${ }^{39}$; lo que tampoco impedía que los judíos se prestaran entre sí. A pesar de normas y preceptos varios, el sentido práctico de la economía acabará por imponerse dando lugar a préstamos entre todos los habitantes del reino, fuera cual fuese su confesión. Si bien es cierto que, en el caso de Navarra, el mercado crediticio estaba claramente en manos judías. Quizás porque, una vez que se "tolera» la necesidad del crédito para el buen funcionamiento de la economía, parece una solución

35 Vid. Carrasco, Juan. Sinagoga y mercado: estudios y textos sobre judios del reino de Navarra. Pamplona: Gobierno de Navarra, Departamento de Educación y Cultura, 1993, pp. 174-175.

36 Vid. Leroy, Béatrice. «Les comptes d'Abraham Enxoep au début du Xve siècle». Príncipe de Viana, 1977, vol. 34, n.o 146-147, pp. 177-205.

37 Vid. Lacave Riaño, José Luis. "Un contrato de empeño y un poder en un documento hebreo de Tudela». Sefarad, 1984, vol. 44, n. ${ }^{\circ}$ 1, pp. 3-32; ÍD. "Importante hallazgo de documentos hebreos en Tudela». Sefarad, 1983, vol. 43, n. ${ }^{\circ}$ 2, pp. 169-179; Los judios del reino de Navarra, pp. 376 y ss.

38 Vid. Elía Muñáriz, Alfredo. "El crédito cristiano en el mercado de Pamplona. 1330-1360». Huarte de San Juan. Geografía e Historia, 1995, vol. 2, pp. 9-58.

39 La idea que inspira la ley que prohíbe el préstamo entre hermanos queda ya recogida en el texto bíblico (Éxodo 22:24). Se repite en la Misná: BM 5:6 «Se puede prestar y tomar préstamo con interés de un gentil». Y se reincide sobre ello en el Talmud: BM 61b «El Santo, bendito sea, declaró: ...seré yo quien tome venganza en el que atribuya su dinero a un gentil y se lo preste a un israelita con interés» 
aceptable dejar el préstamo en manos de los judíos, permitiendo así el desarrollo económico sin incumplir la normativa eclesiástica ${ }^{40}$.

$\mathrm{Al}$ igual que el resto de las actividades financieras, el préstamo está regulado durante toda la Edad Media por distintos ordenamientos con el fin de impedir posibles abusos. Para ello se establece una tasa de interés que no puede ser sobrepasada y que se fija en diferentes porcentajes en cada reino hispánico. En Navarra se fija en un $20 \%$ en el Amejoramiento de Felipe III de 1330, y parece que en reinados posteriores se mantiene asít ${ }^{4}$. En cualquier caso, por los documentos no podemos saber si se respetaba la tasa de interés, pero es muy probable que no se cumpliera siempre. Es un hecho probado a lo largo de la historia que la aplicación de una ley lleva consigo la estrategia para evadirla. Se empleaba, por ejemplo, diferente tipo de monedas, o se pagaba en especie, pudiendo así especular dentro de una aparente legalidad, tal y como se refleja en el capítulo de penas del Procurador fiscal que mencionamos arriba. Hay que recordar, en este sentido, que el préstamo era una actividad provechosa, pero muy arriesgada. El prestamista corría el peligro permanente de no recuperar su dinero por la continua inestabilidad de la época, debida a guerras, pestes o malas cosechas, y quizás por esta razón el interés fijado no era nunca lo suficientemente alto para el que prestaba.

En uno de los documentos hebreos conservados se observan las dificultades de una familia para asumir los pagos obligados por tener préstamos pendientes de cobro. Se trata de la familia de Mosse Evenayón, robado y asesinado por un cristiano. En su libro de registro leemos la lista de sus deudores cristianos, especificando nombre y lugar de residencia, cuantía de la deuda, plazo de amortización, y garante de la misma. Algunas de estas deudas eran muy difíciles de cobrar, y era importante que esta dificultad quedase claramente reflejada, para justificar así ante el fisco el impago de los impuestos devenidos de los beneficios que se obtenían por los préstamos. En caso de no ser posible cobrar una deuda, tenían que figurar las razones bien descritas para justificarse ante la Hacienda real. En el libro se lee: «De aquí en adelante todas las cartas de deudas consignadas en este libro son muy malas, pues de algunas, los deudores han huido, y de otras no se les encuentra nada para cobrárselas porque están en la pobreza extrema $»^{42}$. Los judíos pagaban al rey en función de sus ingresos y patrimonio; por ello era importante que estuvieran reflejados minuciosamente en estos registros las propiedades y ganancias del prestamista. De este modo, el fisco podía considerar circunstancias especiales y contemplar otro modo de recaudar el dinero debido.

Los prestatarios de los judíos pertenecían a distintos estamentos y se ocupaban de distintas actividades, a saber: campesinos, artesanos, nobles, clérigos y oficiales reales. A su vez, los judíos que prestaban dinero realizaban distintas actividades; y tenían, por lo general, una profesión diferente de la de prestamista. Se trataba, en la mayor parte de los casos, de artesanos o mercaderes que prestan ocasionalmente, probablemente como

40 Vid. Shatzmiller, Joseph. Shylock Reconsidered. Jews, Moneylending, and Medieval Society. Berkeley: University of California Press, 1990, p. 44.

41 López Elum, Pedro. "Datos sobre la usura en Navarra en los comienzos del siglo xv». Príncipe de Viana. 1971, vol. 32, n. ${ }^{\circ}$ 124-125, pp. 257-262.

42 Lacave, Los judios del reino de Navarra, n. ${ }^{\circ} 30$. 
DOCUMENTOS HEBREOS DEL REINO DE NAVARRA. UNA REFLEXIÓN SOBRE SU ALCANCE HISTÓRICO-LINGÜÍSTICO EUNATE MIRONES LOZANO

una forma de invertir el dinero obtenido de los beneficios de sus negocios y, por tanto, como una actividad secundaria ${ }^{43}$. Tal y como sucedía con los judíos que se ocupaban de tributar, que tenían un oficio propio y la recaudación solía ser una ocupación subsidiaria. Los judíos navarros se dedicaban sobre todo al comercio y la artesanía, y así encontramos menciones de judíos plateros ${ }^{44}$, pellejeros ${ }^{45}$, fruteros ${ }^{46}$, despenseros de la reina ${ }^{47}$, corredores $^{48}$, peleteros ${ }^{49}$, sastres $^{50}$, libreros ${ }^{51}$, y fisicos o cirurgicos $^{52}$. También les encontramos ocupándose de actividades que no asociamos normalmente a esta minoría, como la guarda y cuidado de animales: Abraham Maçanas, de Olite, guarda la leona del Príncipe ${ }^{53}$; en 1446 se le encomienda a un tal Martín Tamariz que lleve «una onssa, de Ollit a Tudela, para que la criassen los judios»" ${ }^{54}$; a una judía, también de Olite, Çinqua (sic), se le paga un dinero por «sus trauaios de la goarda de la leona» ${ }^{55}$.

\section{LAS LENGUAS DE LOS JUdíOS NAVARRos}

«Item nuyl corredor nonsia usado que faga mercaderia ninguna que compre nin venda entre ningunas personas, faulando en algarabía ni en abraych nin en basquenç: et qui lo fara pague por coto xxx sol. Anyo 1349».

Así reza un documento encontrado en el Archivo Municipal de Huesca, redactado a mediados del siglo XIV, y que contiene una larga ordenanza municipal, en uno de cuyos apartados se prohíbe a los corredores «hacer mercadurias» en árabe, hebreo o euskera. La labor de estos corredores era hacer legales los acuerdos de compraventa. A decir de los entendidos, no es probable que prohibiesen el uso de estas lenguas para que los navarros que venían al mercado no engańasen a nadie a la hora de hacer tratos ${ }^{56}$. En cualquier caso, lo que nos interesa del documento es que da testimonio del uso, en un territorio

43 Romano considera el préstamo como una actividad secundaria que serviría únicamente de apoyo a los ingresos obtenidos a través de un oficio; vid. Romano, David. «Prestadores de judíos en los estados hispánicos medievales». Estudios Mirandeses, 1988, vol. 8, pp 117-126, esp. p. 123. A este respecto vid. también, Carrasco, Sinagoga, pp. 305-331.

44 AGN, Comptos, caj. 126, n. ${ }^{\circ} 27$, VII.

45 AGN, Comptos, caj. 170, n. ${ }^{\circ} 3$, XXII; caj. 158, n. ${ }^{\circ} 48, \mathrm{I}$.

46 AGN, Comptos, caj. 156, n. ${ }^{\circ} 2$, IV.

47 AGN, Comptos, caj. 162, n. ${ }^{\circ} 43$, II.

48 AGN, Comptos, caj. 132, n. ${ }^{\circ} 44, \mathrm{~V}$.

49 AGN, Comptos, caj. 130, n. ${ }^{\circ} 16$, IX.

50 AGN, Comptos, caj. 172, n. ${ }^{\circ}$ 9, XXVII.

51 AGN, Comptos, caj. 147, n. ${ }^{\circ}$ 3, LXVII; caj. 147, n. ${ }^{\circ}$ 6, LXVI.

52 En una ocasión aparece una denominación algo distinta; en un documento de 1452 se menciona al judío Mosse "fisico en medezina» (AGN, Comptos, caj. 156, n. ${ }^{\circ}$ 62, XVI).

53 AGN, Comptos, caj. 143, n. ${ }^{\circ} 46$, II; caj. 142, n. ${ }^{\circ} 22$, XXIII; caj. 144, n. ${ }^{\circ}$ 2, I.

54 AGN, Comptos, caj. 154, n. ${ }^{\circ}$ 18, VIII. La «onza» era un mamífero similar a las panteras, pero domesticable y que en Persia se utilizaba para cazar gacelas.

55 AGN, Comptos, Reg. 461, fol. XIV.

56 Vid. Latiegi Eraso, Bixente. "El euskera en la Huesca de los siglos XIV al XviI». Boletín de la Real Sociedad Bascongada de Amigos del País, 2002, vol. 58, n. ${ }^{\circ}$ 1, pp. 5-28. 
próximo a la frontera navarra ${ }^{57}$, probablemente por gentes venidas de aquel reino, de las dos lenguas que interesan a nuestro estudio: el hebreo y el euskera.

En el caso de los judíos, su lengua de expresión corriente en los siglos XIV y XV era el romance navarro, que se hablaba en las principales poblaciones del reino y era lengua administrativa de la corte desde el siglo $\mathrm{XIII}^{58}$. Sin embargo, los documentos descritos muestran irrefutablemente que utilizaban también la lengua hebrea, y es nuestro propósito tratar de entender por qué escribían estos textos en hebreo y en qué contexto se elaboraban. Asimismo, nos interesa saber si el llamativo número de judíos navarros portadores de sobrenombres en lengua vasca es señal de un vínculo y conocimiento de esta lengua menos superficial del que se presuponía hasta la fecha ${ }^{59}$.

\subsection{Lengua hebrea}

En la Edad Media el hebreo era la lengua en la que se comunicaban entre sí eruditos, juristas y hombres de letras, tanto en Navarra como en el resto de reinos cristianos de la Península. Era la lengua en la que se rezaba y se intercambiaba conocimiento, científico y religioso. Benjamín de Tudela, judío preparado y bien formado, hijo de un rabino de su comunidad, escribe su libro de viajes en hebreo, y en hebreo se comunica con los judíos que irá encontrando a lo largo de su periplo ${ }^{60}$. La lengua hebrea, en su mejor versión, siempre permaneció viva entre la élite, una parte muy pequeña de la sociedad judía que no representaba a la mayoría. Sin embargo, la mayor parte de los judíos aprendían el alefato hebreo a muy temprana edad para su instrucción religiosa, y los judíos navarros no eran una excepción. Así pues, muchos judíos eran capaces de leer y escribir en hebreo, si bien en una lengua rudimentaria y ajena a florituras ${ }^{61}$. Su gramática y léxico eran insuficientes, de ahí el uso frecuente de voces romances en estos escritos, en los que se insertaban palabras, frases e incluso párrafos en aljamía. Su sintaxis, inmadura, deja entrever asimismo su lengua de habla, que se contagia a su vez del hebreo en expresiones romances contaminadas de usos propios de la lengua hebrea ${ }^{62}$. El romance navarro que, en la mayoría de los casos, no sabían leer ni escribir, era su lengua de comunicación natural, y es lógico que el hebreo con el que escriben esté contagiado de sus usos.

57 Lopez-Mugartza Iriarte, Juan Karlos. Erronkari eta Ansoko toponimiaz. Pamplona: Euskaltzaindia, 2008, p. 177; GonZÁlez Ollé, Fernando. Vascuence y romance en la historia lingüística de Navarra. Pamplona: Ediciones y Libros, 1972.

58 Vid. Cierbide Martinena, Ricardo. «Plurilingüismo histórico en Euskal Herria». Fontes Linguae Vasconum, 1990, vol. 22, n. ${ }^{\circ}$ 56, pp. 156 y ss.

59 Vid. Magdalena Nom de Déu, José Ramón. "Judeorromances "marginales" de Sefarad». Miscelánea de Estudios Árabes y Hebraicos, 1988-1989, vol. 33, pp. 41-53.

60 Magdalena Nom de Déu, José Ramón. Libro de viajes de Benjamin de Tudela. Versión castellana, introducción y notas. Barcelona: Riopiedras Ediciones, 1982. Aragón.

${ }_{61}$ Navarra no es un caso único; este tipo de documento existe también en los reinos de Castilla y

62 Por ejemplo, haciendo uso del constructo hebreo, o confundiendo géneros y adjetivando el nombre romance con el género que correspondería a la palabra hebrea. 
DOCUMENTOS HEBREOS DEL REINO DE NAVARRA. UNA REFLEXIÓN SOBRE SU ALCANCE HISTÓRICO-LINGÜÍSTICO EUNATE MIRONES LOZANO

Lo que muestran estos documentos hebreos, en definitiva y sin asomo de duda, es un testimonio directo e irrefutable del uso de esta lengua en el momento de su redacción, tanto en el caso de los documentos públicos como en el de los privados. Los documentos comunitarios los redactaba el escriba o sofer, en un hebreo muy superior al de los documentos privados, ya que se le exigía una competencia lingüística superior que se adecuara a las normas y estilo de la escritura jurídica. Se observa este nivel de lengua en las ordenanzas de la comunidad judía de Tudela, en la sesión del tribunal rabínico y en los contratos matrimoniales. Estos documentos públicos, redactados con propiedad y corrección, son de gran importancia e interés por su contenido y forma. Sin embargo, para comprender las herramientas reales de expresión de los judíos navarros, la realidad lingüística de la comunidad, resultan mucho más interesantes los documentos de orden privado. Los libros de cuentas de particulares, si bien adolecen de la idoneidad lingüística de los textos comunitarios, se convierten en expresiones más directas y fidedignas del uso real y cotidiano de la lengua hebrea. Además, no siempre se redactaban en un hebreo pobre, con voces o expresiones romances insertadas a lo largo del texto. Algunos de estos documentos, aun siendo su redacción muy inferior a la del escriba profesional, están redactados en su totalidad en un hebreo que denota un conocimiento razonable de la lengua. A los textos escritos íntegramente en hebreo se les anexaba un resumen del contenido en aljamía hebraica, para hacerlo así comprensible al judío que no era capaz de entender el hebreo.

\subsection{Lengua vasca}

Hasta aquí queda claro que los judíos, en los años a los que pertenecen los documentos hebreos objeto de este estudio, se comunicaban entre sí en romance navarro, y había un número indeterminado de judíos capaces de escribir en hebreo con más o menos solvencia. ¿Qué ocurría con la lengua vasca, lengua vernácula de Navarra; cuál era la relación de los judíos navarros con esta lengua, si es que la había? A pesar de que esta lengua no se escribía prácticamente, ya que la población que la hablaba era en su mayor parte ágrafa, no se cuestiona que fuera entonces lengua viva. Así lo confirman testimonios documentales como la ordenanza que prohíbe su uso con la que se introduce esta sección; o las conocidas frases en euskera, intercambiadas en un recibo de las cuentas reales de 1415 entre dos funcionarios ${ }^{63}$.

Si el euskera no se escribía apenas, siendo los testimonios escritos rarísimos de mano cristiana, difícilmente vamos a encontrar judíos escribiendo en lengua vasca, lo que no quiere decir necesariamente que no lo hablaran. Los judíos hablaban las lenguas de los lugares en los que residían, y a los que pertenecían después de generaciones. Por otro lado, siempre se les ha atribuido una proverbial poliglotía, y parece probado que poseían tal facultad. Por lo general adquirían y hacían suyas las lenguas con las que estaban en

63 IdoAte, Florencio. "Una carta del siglo xv en vascuence». Fontes Linguae Vasconum, 1969, vol. 1, n. ${ }^{2}$, pp. $287-290$. 
contacto $^{64}$. No podemos demostrar que ocurriera así con el euskera, aunque no nos resulta del todo convincente la teoría que dice que los judíos de territorio vascófono no tenían vinculación alguna con el euskera porque residían en núcleos urbanos de cierta envergadura, donde el romance era la lengua principal de comunicación; y pocas veces se encuentran judíos en entornos rurales, en los que la lengua vasca era preponderante. No hay que olvidar que esta población de habla vasca, que se concentra en la parte más montańosa e inaccesible del reino, va a descender paulatinamente a la planicie a lo largo de la Edad Media en busca de mejores condiciones económicas, y sus pobladores llevarán consigo su lengua ${ }^{65}$.

Los judíos navarros utilizaban en esta época sobrenombres en hebreo, romance y euskera. Creemos que el hecho de que utilicen la lengua vasca para nombrarse es muestra de un lazo muy estrecho con el territorio navarro y un síntoma inequívoco de integración. Otorgarse un nombre no es, ni ha sido nunca, un gesto arbitrario en cultura alguna conocida. Muy al contrario, es un acto definitorio que se cuida mucho y raramente se deja al azar. Es cierto que el uso de un sobrenombre en lengua vasca no da testimonio del conocimiento efectivo de esta lengua; y es obvio que uno puede llevar un sobrenombre sin conocer su significado. Así, pues, el nombrarse de esta manera no demuestra necesariamente que hablaran vasco, ni siquiera que conocieran el significado de los apellidos ${ }^{66}$ o sobrenombres que les denominaban. No obstante, nos inclinamos a pensar que es muy probable que sí los entendieran, porque en más de una ocasión todo parece indicar que el judío que aparece en el documento es uno de los primeros portadores del apodo o sobrenombre que le titula. Sería extraño que uno no entienda el sobrenombre con el que le identifican siendo el primero que lo acuña.

Tenemos, por ejemplo, el caso de Judas Alborge, llamado Ederra 'hermoso' ${ }^{\prime 67}$. Ederra acabará por ser un apellido; sin embargo, aquí lo encontramos todavía en estadio de sobrenombre o apodo. Parece difícil creer que su portador, con toda probabilidad el primero, no entendiera el sobrenombre con el que le identificaban. Cuando estos apodos se transforman en apellidos, al pasar de padres a hijos a lo largo de generaciones, pueden empezar a funcionar tan solo como identificadores que no refieren ya ninguna característica particular de su portador y que, en ocasiones, carecen de significado para el que lo lleva. Sin embargo, para que esto ocurra, para que el apodo pierda por completo su sentido original, y ya nadie comprenda lo que significa, han de pasar muchos años. El sobrenombre Ederra, funcionando ya como apellido, aparece con especial profusión, y

${ }^{64}$ Por ejemplo, el catalán, riquísimo en documentación que atestigua su uso; vid. MagdalEna Nom DE DÉU, "Judeorromances», pp. 46 y ss. Consúltese, asimismo, RiERA I SANS, Jaume. «Cent trenta-nou volums de llibres d'un jueu mercader i talmudista: Mossé Almaterí (1362)». Sefarad, 2008, vol. 68, n. ${ }^{\circ}$ 1, pp. 15-35.

65 Son muchos los trabajos realizados hasta la fecha para entender la evolución de la lengua vasca y su desplazamiento dentro de la geografía navarra y tierras colindantes, entre otros, los estudios de Michelena, Lafon y Trask (vid. referencias bibliográficas).

66 Utilizo el término «apellido», consciente de que no es del todo adecuado en época medieval. Se hace así para no llevar a confusión y distinguirlo claramente del término «sobrenombre» con el que nos referimos a apodo.

Navarra Judaica, $3^{* *}$, n. ${ }^{\circ}$ 680-679. 
DOCUMENTOS HEBREOS DEL REINO DE NAVARRA. UNA REFLEXIÓN SOBRE SU ALCANCE HISTÓRICO-LINGÜÍSTICO EUNATE MIRONES LOZANO

más frecuentemente que su forma hebrea Jaffe ${ }^{68}$, o su equivalente romance: Hermoso ${ }^{69}$. Otros testimonios de nombres vascos, aún en estadio de sobrenombre o apodo, de los que no hemos encontrado equivalente ni en romance ni en hebreo, son Chacur ${ }^{70}$ "perro" y Beltza $a^{71}$ "negro». Ya formados como apellidos tenemos: Bildocha "cordero»; Motç "corto»; Çuri «blanco»; Ossaba «tío»; Ezquerra "zurdo» y Mehe "delgado».

La posibilidad de que los judíos navarros estuviesen familiarizados con la lengua vasca hasta el punto de utilizarla queda en suposición, altamente probable, pero suposición, puesto que no se conserva documentación que lo acredite de forma irrefutable. Sin embargo, el hecho de que no existan documentos de este tipo, o no se hayan conservado, caso de existir, no es tampoco razón suficiente para afirmar taxativamente que no ocurriera. Los testimonios que aportamos, dependiendo de la interpretación que se haga de ellos, resultan en evidencias valiosas a la hora de argumentar a favor de una más que posible familiaridad con la lengua vasca por parte de la minoría judía del reino navarro. Es difícil creer que se trate únicamente de la adopción automática de sobrenombres vascos usados por los cristianos. Nos inclinamos a pensar que optaban por el sobrenombre eusquérico con plena conciencia de hacerlo, sencillamente porque les resultaba natural.

La lógica nos empuja a suponer que habría judíos navarros, no olvidemos que eran judíos sí, pero primero y antes de nada navarros, con un conocimiento mayor o menor de la lengua vasca. Es también probable que, dependiendo de la zona geográfica del reino, el oficio, y la misma necesidad según los casos, hubiera judíos que se comunicaran ocasionalmente en esta lengua con vecinos cristianos vasco-parlantes; con habitantes del reino para los que el euskera era su primer, y a veces único, medio de expresión, resultándoles difícil comunicarse en romance con fluidez. No es un desatino, en fin, pensar que en algún momento los judíos, por diversos motivos o intereses, tuvieran la necesidad de comunicarse en esta lengua que, aunque no era la lengua oficial del reino, tenía presencia y arraigo indiscutibles.

\section{Conclusión}

En términos generales, la documentación en romance referida a judíos navarros nos informa sobre sus profesiones, su reparto geográfico, número de hogares y participación en las cuentas del reino. Para precisar más adecuadamente el nivel de integración y convivencia de esta minoría en la sociedad cristiana de la época, es fundamental recurrir a la documentación conservada en hebreo y aljamía hebraica. Esta última revela información muy valiosa, que los documentos en romance no son susceptibles de ofrecer, completando y enriqueciendo la panorámica. Los manuscritos que contienen las ordenanzas de la comunidad, la sesión del tribunal rabínico, y los contratos matrimoniales, muestran,

68 Navarra Judaica, 4, n. ${ }^{\circ} 2-107$.

69 Navarra Judaica, $3^{* *}$, n. ${ }^{\circ} 685$.

70 Simuel Alfaqui, dito Chacur (AGN, Comptos, Reg. 460, fol. CLXXXVv).

71 Juçe Amatu, dito Belcha (AGN, Comptos, Papeles Sueltos, leg. 167, carpeta 33, fol. VIIv). 


\author{
DOCUMENTOS HEBREOS DEL REINO DE NAVARRA. \\ UNA REFLEXIÓN SOBRE SU ALCANCE HISTÓRICO-LINGÜÍSTICO \\ EUNATE MIRONES LOZANO
}

entre otras cosas, que son una comunidad con capacidad organizativa y jurídica para tratar los asuntos que les conciernen en exclusiva. Por otro lado, los documentos que se ocupan de asuntos económicos refrendan las noticias que se infieren de la documentación romance, dando testimonio de una comunidad viva y dinámica, que participa de la economía del reino a todos los niveles.

Por otro lado, los documentos redactados en hebreo y aljamía hebraica tienen capacidad de dar noticias más allá de las estrictamente económicas, o de organización comunitaria. Nos permiten estudiar la realidad plurilingüe de esta comunidad. Constatamos, gracias a esta documentación, que se comunicaban habitualmente en romance navarro, que algunos eran capaces de leer y escribir en hebreo, y que estaban familiarizados con el euskera. La utilización por parte de la minoría judía de las lenguas vernáculas habladas entonces en el reino navarro es un indicador determinante de convivencia e integración, en especial en el caso de la lengua vasca, estrechamente vinculada a la tierra que habitan. Los testimonios documentales de judíos con sobrenombres en euskera, sin ser concluyentes, nos obligan a reflexionar y reconsiderar su relación con esta lengua. Estos se crean espontáneamente y utilizando la lengua de uso común. Si admitimos que es muy posible que los judíos referidos entiendan lo que sus sobrenombres vascos quieren decir, parece razonable confirmar cierto conocimiento de la lengua vasca.

\section{REFERENCIAS BIBLIOGRÁFICAS}

Assís, Yom Tov; Magdalena Nom de Déu, José Ramón y Lleal Galcerán, Coloma. Navarra hebraica. Estudio lingüistico de la aljamía romance en los documentos hebraiconavarros. Barcelona: Universidad de Barcelona, 2003.

BAER, Ytzhak. Historia de los judios en la España cristiana. Madrid: Altalena, 1981.

Carrasco, Juan. Sinagoga y mercado: estudios y textos sobre judios del reino de Navarra. Pamplona: Gobierno de Navarra, Deprtamento de Educación y Cultura, 1993.

Carrasco Pérez, Juan; Miranda García, Fermín y Ramírez Vaquero, Eloísa (compiladores). Navarra judaica: documentos para la historia de los judios del reino de Navarra. Pamplona: Gobierno de Navarra, Departamento de Educación y Cultura, 1994-2003.

Carrasco Pérez, Juan. «El crédito judío en el reino de Navarra, según los padrones de deuda hebreos (1323-1328)». En Val Valdivieso, M. ${ }^{a}$ Isabel del y Martínez Sopena, Pascual (coords.). Castilla y el mundo feudal. Homenaje al profesor Julio Valdeón. Valladolid, 2009, vol. 2, pp. 237-249.

Carrasco Pérez, Juan. «Notariado y Hacienda Pública en el reino de Navarra. El devengo de los sellos del rey. 1294-1414». Príncipe de Viana, 2013, vol. 74, n. ${ }^{\circ} 257$, pp. 111-191.

Castaño GonzÁlez, Javier. "Ketubbot” en-cubiertas: fuentes para el estudio del matrimonio judío en Jaca y los Almosnino». Sefarad, 2009, vol. 69, n. ${ }^{\circ}$ 1, pp. 43-73.

Cierbide Martinena, Ricardo. «Plurilingüismo histórico en Euskal Herria». Fontes Linguae Vasconum. 1990, vol. 22, n. ${ }^{\circ}$ 56, pp. 149-164.

Elía Muñáriz, Alfredo. «El crédito cristiano en el mercado de Pamplona. 1330-1360». Huarte de San Juan. Geografia e Historia, 1995, vol. 2, pp. 9-58.

García Arancón, Raquel. «Marco jurídico y proyección social de las minorías navarras: judíos y mudéjares (siglos XII-Xv)». Iura Vasconiae, 2007, vol. 4, pp. 459-516. 
DOCUMENTOS HEBREOS DEL REINO DE NAVARRA. UNA REFLEXIÓN SOBRE SU ALCANCE HISTÓRICO-LINGÜÍSTICO EUNATE MIRONES LOZANO

García Fernández, Ernesto y Vítores Casado, Imanol (eds.). Tesoreros, «arrendadores» y financieros en los reinos hispánicos. La Corona de Castilla y el Reino de Navarra (siglos XIV-XVII). Madrid: Instituto de Estudios Fiscales, 2012.

González Ollé, Fernando. Vascuence y romance en la historia lingüística de Navarra. Pamplona: Ediciones y Libros, 1972.

IdoAte, Florencio. «Una carta del siglo xv en vascuence». Fontes Linguae Vasconum, 1969, vol. 1, n. ${ }^{\circ} 2$, pp. 287-290.

Ilarregui, Pablo y Lapuerta, Segundo (eds). Fuero General de Navarra. Pamplona: Imprenta Provincial, 1869.

Lacave, José Luis. "Tres nuevas ketubbot españolas». En The History of the Jewish People. From the Second Temple period until the Middle Ages. Jerusalén, 1985, vol. 1, pp. 91-96.

Lacave, José Luis. Los judios del reino de Navarra. T. 7, Documentos hebreos 1297-1486. Pamplona: Gobierno de Navarra, 1998.

Lacave, José Luis. Medieval Ketubot from Sefarad. Jerusalén: Magnes Press, 2002.

LaCaVe Riaño, José Luis. «El contrato matrimonial entre los judíos navarros». Estudios Mirandeses, 1988, vol. 8, pp. 91-99.

Lacave Riaño, José Luis. «Importante hallazgo de documentos hebreos en Tudela». Sefarad, 1983, vol. 43, n. ${ }^{\circ}$ 2, pp. 169-179.

Lacave Riaño, José Luis. "Un contrato de empeño y un poder en un documento hebreo de Tudela». Sefarad, 1984, vol. 44, n. ${ }^{\circ}$ 1, pp. 3-32.

Lacave Riaño, José Luis. "Un interesante documento hebreo de Tudela». En Exile and diaspora. Studies in the History of the Jewish People presented to Professor Haim Beinart. Jerusalén: Consejo Superior de Investigaciones Científicas-Instituto Ben-Zvi, 1991, pp. 131-145.

Lafon, René. La langue basque. Bayonne: Bulletin du Musée Basque, 1973.

Latiegi Eraso, Bixente. «El euskera en la Huesca de los siglos xiv al xviI». Boletín de la Real Sociedad Bascongada de Amigos del País, 2002, vol. 58, n. ${ }^{\circ}$ 1, pp. 5-28.

Leroy, Béatrice. «Les comptes d'Abraham Enxoep au début du $\mathrm{xv}^{\mathrm{e}}$ siècle». Príncipe de Viana, 1977, vol. 34, n. ${ }^{\circ}$ 146-147, pp. 177-205.

Llamas, P. J. «Documentos para la historia jurídica de las aljamas hebreas de Toledo y Molina». Religión y Cultura, 1932, vol. 19, pp. 263-276.

López Elum, Pedro. «Datos sobre la usura en Navarra en los comienzos del siglo xv». Príncipe de Viana. 1971, vol. 32, n. ${ }^{\circ} 124-125$, pp. 257-262.

Lopez-Mugartza Iriarte, Juan Karlos. Erronkari eta Ansoko toponimiaz. Pamplona: Euskaltzaindia, 2008.

Magdalena Nom de Déu, José Ramón. «Judeorromances “marginales” de Sefarad». Miscelánea de Estudios Árabes y Hebraicos, 1988-1989, vol. 33, pp. 41-53.

Magdalena Nom de Déu, José Ramón. Libro de viajes de Benjamín de Tudela. Versión castellana, introducción y notas. Barcelona: Riopiedras Ediciones, 1982.

Michelena, Koldo. La lengua vasca. Durango: Leopoldo Zugaza, 1977.

Mirones Lozano, Eunate. «Mehe: un apellido vasco escrito en aljamía hebraico-navarra». Fontes linguae vasconum, 2009, vol. 41, n. ${ }^{\circ} 110$, pp. 117-124.

Moliner, María. Diccionario de uso del español. Madrid: Gredos, 1970.

Moreno Koch, Yolanda. Fontes Iudaeorum Regni Castellae. V. De iure hispano-hebraico. Las Taqqanot de Valladolid de 1432. Salamanca: Universidad Pontificia de Salamanca, 1987.

Motis Dolader. Miguel Ángel. «Estructura interna y ordenamiento jurídico de las aljamas judías del Valle del Ebro». En Iglesia Duarte, José Ignacio de la (coord.). II Semana de Estudios Medievales. Logrońo: Instituto de Estudios Riojanos, 1992, pp. 111-152. 
DOCUMENTOS HEBREOS DEL REINO DE NAVARRA.

UNA REFLEXIÓN SOBRE SU ALCANCE HISTÓRICO-LINGÜÍSTICO

EUNATE MIRONES LOZANO

Mugueta Moreno, Ínigo. «Las demandas del rey de Navarra: vocabulario, discurso e identidades fiscales (1300-1425)». Anuario de Estudios Medievales, 2014, vol. 44, pp. 911-943.

Muñoz Solla, Ricardo. "Dos "ketubbot" castellanas y otro fragmento hebreo del Archivo de la Real Chancillería de Valladolid». Sefarad, 2014, vol. 74, n. ${ }^{\circ}$ 2, pp. 343-368.

Neusner, Jacob. «Studies on the Taqqanot of Yavneh». Harvard Theological Review, 1970, vol. 63, pp. 183-198.

OngaY, Nelly. El registro del «veinteno» en Tudela. 1362. Mendoza: Universidad Nacional de Cuyo, 1997.

Riera I SANS, Jaume. «Cent trenta-nou volums de llibres d'un jueu mercader i talmudista: Mossé Almaterí (1362)». Sefarad, 2008, vol. 68, n. ${ }^{0}$ 1, pp. 15-35.

Romano, David. «Prestadores de judíos en los estados hispánicos medievales». Estudios Mirandeses, 1988, vol. 8, pp 117-126.

Shatzmiller, Joseph. Shylock Reconsidered. Jews, Moneylending, and Medieval Society. Berkeley: University of California Press, 1990.

Trask, R. L. The History of Basque. London: Routledge, 1997.

Zabalo Zabalegui, Javier. La Administración del Reino de Navarra en el siglo XIV. Pamplona: Eunsa, 1973. 
